\title{
Analyze of Slight \& Sever Injury Resulted from Traffic Accidents in Jordan: Applied Statistics Study
}

\author{
Adeeb Ahmed Ali AL Rahamneh ${ }^{1}$ \\ ${ }^{1}$ Applied Statistics, Faculty of Business, AL Balqa Applied University, Jordan \\ Correspondence: Adeeb Ahmed Ali AL Rahamneh, Applied Statistics, Faculty of Business, AL Balqa Applied \\ University, Jordan. E-mail: moheeb982005@yahoo.co.uk
}

Received: November 19, 2015

Accepted: December 21, 2015

Online Published: January 23, 2016

doi:10.5539/ijbm.v11n2p323

URL: http://dx.doi.org/10.5539/ijbm.v11n2p323

\begin{abstract}
This study aims at show the size of the injuries, both slight and sever caused by traffic accidents on the roads in Jordan for the year 2014, and show the relationship of both slight and sever injuries caused by traffic accidents with the study variables used in this paper performed using the (SPSS). Based on the analysis made, the following are the main results:

There is statistical significant relationship between type of injury (slight, sever) and accident type, time, month, governorate, light condition, age group, speed limit at (0.05) level.

There is no statistical significant relationship between type of injury (slight, sever) and weekdays, territory, weather condition, gender.

This work has been carried out during sabbatical leave granted to the author (Adeeb A AL Rahamneh) from AL Balq'a Applied University (BAU) during the academic year(1/2/2015-1/2/2016).
\end{abstract}

Keywords: traffic accidents, slight injury, sever injury, accident type, time, governorate, light condition, age group, speed limit, weather condition

\section{Introduction}

The traffic accidents is considered of the most important and the most sever problems facing societies around the world, where it consumes a considerable amount of human and material resources. The statistics issued by the World Health Organization suggest that the world loses annually approximately 1.2 million people, are infected annually (20-50) million person in the world because of traffic accidents, as well as high material costs resulting from these accidents is estimated at 518 billion US dollars for all countries of the world and what constitutes $(1 \%-3 \%)$ of the gross domestic product around the world.

Many countries of the world have come to the need to develop strategies and national mechanisms to address the safety challenges of traffic associated with many of the related sectors and bodies. The World Health Organization considered traffic accidents of the most important causes of death. The governments of the world appealed to deal with it, and that man has succeeded in eliminating many of diseases and epidemics and tempered the intensity and severity of these epidemics and diseases that kill humans, but he replaced them with traffic accidents.

In Jordan, one of the developing countries is suffering as the rest of the world from the scourge and secretions of this problem which has become an insurmountable problem; and this problem acquired a great interest from the Jordanian governments. The number of traffic accidents in Jordan for the year 2014, was (102441), of which (69395) traffic accidents is equivalent to (68\%) in the capital, Amman alone, and resulted (688) deaths, including 193 deaths, equivalent to (28.05\%) in the capital, Amman, alone and injured (14790) person, including (5689) injury which is equivalent to (38.47\%) in the capital, Amman, distributed to (2063) sever injury and (12727) slight injury, including (698) sever injury which is equivalent to $(33.83 \%)$ and (4991), slight injury which is equivalent to (39.22\%) in the capital Amman. The material costs for the whole of these incidents amounted to 239 million Jordanian dinars and equivalent (approximately 337) million US Dollars.

Jordan is a popular destination for many visitors and Summer vacationist from the world, whether from Arab countries or from foreign countries due to its security grace and stability, as well as laws governing and 
legislation that encourage investment in Jordan, as well as a mild climate and strategic location. As a result of the continuing increase in the number of vehicles, as well as rapid population growth, the problem of traffic accidents have become a problem threatening the security and safety of the Jordanian society, and began to pose a sever consuming of the human and material energies, which adversely affects Jordan 's efforts in development and construction.

We will study both slight and sever injuries resulting from traffic accidents in Jordan for the year 2012 and its relationship with the following variables i:

\subsection{The Research Problem}

The research problem lies in the growing and huge numbers of both slight and sever injuries caused by traffic accidents on the roads in Jordan, and the consequent consuming of enormous material resources represented by the huge material costs, as well as attrition obviously in human energies and tragedies of the secretions injuries represented by the loss of parents, despite of procedures of the relevant authorities.

\subsection{The Research Objectives}

This research aims to:

1) Show the size of the injuries, both slight and sever caused by traffic accidents on the roads in Jordan for the year 2014.

2) Show the relationship of both slight and sever injuries caused by traffic accidents with the study variables using appropriate statistical methods.

3) Study variations in, both slight and sever injuries according to the study variables.

4) Contribute finding the best and most effective solutions to minimize the severness of the problem.

\subsection{The Justification of the Study}

The aggravate of the size of the both slight and sever injuries caused by traffic accidents on the roads in Jordan for the year 2014, and the negative effects and consequences of this problem on the foreign currency assets and the Jordanian economy as a whole.

The need for more in-depth studies to examine the problem in all its aspects.

To acknowledge the size and causes of the problem in order to provide a sufficient indication of the magnitude and severness of the, both slight and sever injuries caused by traffic accidents .

The high financial cost of both slight and sever injuries caused by traffic accidents.

\subsection{Methodology}

The descriptive statistics method represented by percentages and graphs is used, as well as the use of advanced statistical methods such as:

I) Two-way Anova.

II) Chi-Square Test.

\subsection{Time Limits}

Both slight and sever injuries, caused by traffic accidents on the roads in Jordan for the year 2014 , the latest available data to date, will be analyzed .

\subsection{Spatial Limits}

Both slight and sever injuries caused by traffic accidents on the roads in Jordan within the geographical border of the Jordanian Hashemite Kingdom border will be analyzed.

\subsection{The Procedural Definitions}

The operation definition of the major concepts (Traffic Accident, Slight Injury, Sever Injury) derived from definitions in (http://www.jti.jo)

\section{Previous Studies}

Deven Lefler and Hampton Gabler (2014). This Article investigated the effect of striking vehicle type on pedestrian fatalities and injuries. The paper presents and compares pedestrian impact risk factors for sport utility vehicles, pickup trucks, vans, and cars as developed from analyses of US accident statistics. The analysis revealed that given an impact speed, the probability of serious head and thoracic injury is substantially greater when the striking vehicle is an LTV rather than a car. 
$\mathrm{Hu}$ and Xiang (2012). This paper explored the characteristics of traffic accidents on rural roads by quantitative analysis in terms of accident forms, road alignment, roadside protection, intersection types, regional economic situation, accident time, and vehicle features. The results showed that traffic accidents on rural roads were prone to the developed area. Driving without license and head-on collisions were overwhelmingly dominant Accident related casualties and vehicles including agricultural vehicle and motorcycle are local.

$\mathrm{Li}, \mathrm{Hu}$, and Cao (2012). This paper dealt with certain accident impact factors are often hidden in statistical models due to over-dispersion of traffic accident data. Using 7-year data from grievous accidents in China, this paper carried out a simulated calculation of the proposed model.

The empirical results show that compared to a fixed-parameters NB regression model, random-parameters models are quite enough to characterize the uncertainty of the accident and can greatly improve the validity of the empirical results.

Zhang, Yao, and Li, (2012). This paper first treats the overall situation of road traffic accidents, then goes further to analyze the intrinsic interdependence among four different lighting conditions and respective traffic accidents.

Ma, and Zhang et al. (2011). This paper applied a biochemical factorial experiment method to traffic accidents' inducement analysis, and describes the processes of modeling and data processing in detail.

Li (2011). In this paper, as an example to Harbin, choosing some road sections to observe continuously, based on the urban-rural continuum road conditions and traffic characteristics, using of engineering psychology and accident catastrophe theory, with the main effects of traffic accidents, to ensure the impact of the drivers workload in the road traffic accidents in central cities rural-urban continuum.

Hallvard Gjerde, et al. (2011). This research dealt with drivers fatally injured in road traffic accidents in southeastern Norway during the period 2003-2008. As controls, 10540 drivers selected in a roadside survey in the same geographical area during 2005-2006 were used. Blood samples were collected from the cases and oral fluid (saliva) samples from the controls. Samples were analyzed for alcohol, amphetamines, cannabis, cocaine, opioid analgesics, hypnotics, sedatives and a muscle relaxant; altogether 22 psychoactive substances. concentrations for blood and oral fluid were used. The risk for fatal injury in a road traffic accident was estimated using logistic regression adjusting for gender, age, season of the year, and time of the week.

Golob, and Recker (2003). This paper dealt with how the types of accidents that occur on heavily used freeways in Southern California are related both to the flow of traffic and to weather and ambient lighting conditions. The results indicate that the type of collision is strongly related to median traffic speed and to temporal variations in speed in the left and interior lanes.

Sandvik et al. (2000). The aim of this study was to develop a valid epidemiological instrument (a severity index) for assessing the severity of incontinence. The severity index is based on information about frequency (four levels) and amount of leakage (two or three levels). By multiplication, an index value (1-8 or 1-12) is reached. This index value is further categorized into a severity index of three or four levels. The index was compared with the results of 315 pad-weighing tests performed by 265 women in hospital and general practice. Data from an epidemiological survey were also re-analyzed by applying the four-level severity index.

Mary Tinetti et al. (1995). This research determined the frequency of, and risk factors for, experiencing serious fall injury events among older persons in the community. A representative sample of 1103 community-living persons aged 72 years and older underwent comprehensive baseline and 1-year evaluations. During a median 31 months of follow-up, fall data were obtained using fall calendars. Injury data were obtained from telephone interviews and from surveillance of emergency room and hospital records. At least one fall was experienced by $546(49 \%)$ participants. A total of 123 participants, representing $23 \%$ of fallers and $12 \%$ of the cohort, experienced 183 serious fall injury events.

The factors independently associated with experiencing a serious injury during a fall included cognitive impairment.

\section{Analysis Procedures}

To achieve the objectives of the study, we used the (SPSS) and Minitab ver. (17).

\subsection{Methodology}

In this paper, the researcher used chi-square, Two Way Anova (Abu-Salih \& Awad, 1983). Two-Way (Analysis of Variance), the model: 


$$
\begin{aligned}
& Y_{i j}=\mu+\alpha_{i}+\beta_{j}+\xi_{i j} \\
& i=1,2, \ldots \ldots . . r \\
& j=1.2 \ldots \ldots . c \\
& \sum_{i} \alpha_{i}=\sum_{j} \beta_{j}=0
\end{aligned}
$$

Table 1. Notations

\begin{tabular}{lllll}
\hline & \multicolumn{5}{c}{ Columns } \\
\hline Rows & 1 & 2 & $\mathrm{j}$ & $\mathrm{c}$ \\
1 & $\mathrm{Y}_{11}$ & $\mathrm{Y}_{12}$ & $\mathrm{Y}_{1 \mathrm{j}}$ & $\mathrm{Y}_{1 \mathrm{c}}$ \\
2 & $\mathrm{Y}_{21}$ & $\mathrm{Y}_{22}$ & $\mathrm{Y}_{2 \mathrm{j}}$ & $\mathrm{Y}_{2 \mathrm{c}}$ \\
$\mathrm{i}$ & $\mathrm{Y}_{\mathrm{i} 1}$ & $\mathrm{Y}_{\mathrm{i} 2}$ & $\mathrm{Y}_{\mathrm{ij}}$ & $\mathrm{Y}_{\mathrm{ic}}$ \\
$\mathrm{R}$ & $\mathrm{Y}_{\mathrm{r} 1}$ & $\mathrm{Y}_{\mathrm{r} 2}$ & $\mathrm{Y}_{\mathrm{rj}}$ & $\mathrm{Y}_{\mathrm{rc}}$ \\
\hline
\end{tabular}

$E_{i j} \quad$ are independent. For each I, j. $E_{i j} \sim \mathrm{N}\left(0, \sigma^{2}\right)$

Total Sum of Squares (SST):

$$
\begin{gathered}
\mathrm{SST}=\sum_{i=1}^{r} \sum_{j=1}^{c}\left(Y_{i j}-Y\right)^{2} \\
\mathrm{SST}=\sum_{i=1}^{r} \sum_{j=1}^{c} Y_{i j}{ }^{2}-r c Y^{2}
\end{gathered}
$$

With d.f $=(\mathrm{rc}-1)$

Sum of Squares for Rows (SSR)

$\mathrm{SSR}=c \sum_{i=1}^{r}(\bar{Y} i .-\bar{Y} . .)^{2}$

$\mathrm{SSR}=\mathrm{c} \sum_{i=1}^{r} \bar{Y} i .-r c \bar{Y}^{2}$

With d.f $=(r-1)$

Sum of Squares for Columns (SSC)

$$
\mathrm{SSC}=\mathrm{r} r \sum_{j=1}^{t} \bar{Y}_{. j}-r c \bar{Y}_{. .}^{2}
$$

With d.f $=(\mathrm{c}-1)$;

Sum of Squares for Errors (SSE);

$$
\mathrm{SSE}=\sum_{i=1}^{r} \sum_{j=1}^{c}\left(Y_{i j}-\bar{Y} i \cdot-\bar{Y} \cdot j-\bar{Y}\right)^{2}
$$

$S S E=S S T-(S S R+S S C)$

With degrees of freedom $($ d.f $)=(r-1)(c-1)$, Where $r$ : no. of rows \& $C$ : no. of columns.

Table 2. ANOVA

\begin{tabular}{lllll}
\hline F-Statistic & Mean Squers & Sum of Squares & d.f & Source of Variation \\
\hline FR $=$ MST/MSE & MSR $=\frac{S S R}{r-1}$ & SSR & $\mathrm{r}-1$ & Between Rows \\
$\mathrm{FC}=$ MSB/MSE & $\mathrm{MSC}=\frac{S S C}{c-1}$ & $\mathrm{SSC}$ & $\mathrm{c}-1$ & Between Columns \\
& $\mathrm{MSE}=\frac{S S E}{(r-1)(c-1)}$ & $\mathrm{SSE}$ & $(\mathrm{r}-1)(\mathrm{c}-1)$ & Error \\
& & $\mathrm{SST}$ & $\mathrm{rc}-1$ & Total \\
\hline
\end{tabular}

Chi-Square Test for Independence (M. Abu-Salih \& A. Awad, 1983; Gerald Keller, 2010). 
Chi-square for independent test which is used to determine whether there is a significant relationship between two categorical variables.

\section{Test steps}

State the null hypotheses (Ho), and alternative hypotheses (H1), as:

H0: Variable A and variable B are independent.

$\mathrm{H} 1$ : Variable A and variable B are not independent.

Find the critical value as the following:

$$
\chi^{2}{ }_{t a b=\chi^{2}}[(r-1)(c-1), 1-\alpha]
$$

Where is:

r: No. of rows.

c: No. of columns.

$\alpha$ : significant level.

1) Compute the test value as:

$$
\chi^{2}=\Sigma \frac{(O i-E i)^{2}}{E i}
$$

Where is:

$\mathrm{Oi}=$ Observed value.

$\mathrm{Ei}=$ Expected value, and $\mathrm{Ei}=\frac{\text { RowSumxColumnSum }}{\text { GrandTotal }}$

2) Make the decision

Criteria: If P-value $\leq$ significant level, we reject null hypothesis and accept alternative hypothesis.

\subsection{Assumptions}

The data are obtained from a random sample

The expected value in each cell must be 5 or more.

\subsection{The Hypotheses}

Groupe (I)

Two-way anova

H01: There is no statistical significant relationship at between type of injury (slight, sever) and traffic accident type (Collision, Pedestrian, Turnover) at (0.05) level.

H02: There is no statistical significant relationship at between type of injury (slight, sever) and time (0.00-00.59, $01.00-01.59 \ldots .23 .00-23.59)$ at $(0.05)$ level.

H03: There is no statistical significant relationship at between type of injury (slight, sever) and weekdays (Saturday, Sunday.......Friday) at (0.05) level.

H04: There is no statistical significant relationship at between type of injury (slight, sever) and month (January, February.......December) at (0.05) level.

H05: There is no statistical significant relationship at between type of injury (slight, sever) and governorate (Amman, Irbed ....... Ajoun) at (0.05) level.

H06: There is no statistical significant relationship at between type of injury (slight, sever) and Territory (Central Region, North Region, South Region) at (0.05) level.

H07: There is no statistical significant relationship at between type of injury (slight, sever) and weather condition (Clear, Fog...... Dust) at (0.05) level.

H08: There is no statistical significant relationship at between type of injury (slight, sever) and road surface condition (Dry, Wet......Sandy) at (0.05) level

H09: There is no statistical significant relationship at between type of injury (slight, sever) and light condition 
(Day Light, Night with Sufficient Light. ..Sunset) at (0.05) level.

H10: There is no statistical significant relationship at between type of injury (slight, sever) and age group (0-2, $3-5, \ldots \ldots .60+)$ at $(0.05)$ level.

H11: There is no statistical significant relationship at between type of injury (slight, sever) and speed limits (10, $20, \ldots . .120)$ at $(0.05)$ level.

H12: There is no statistical significant relationship at between type of injury (slight, sever) and gender (Male, Female) at (0.05) level.

Hypothesis testing results as the following:

Table 3. Shown the Chi-Square test for (Ho1, Ho2......H012)

\begin{tabular}{|c|c|c|c|c|c|}
\hline $\begin{array}{l}\text { Hypothesis } \\
\text { No(Ho) }\end{array}$ & Variables & $\begin{array}{l}\text { The } \\
\text { Calculate } \\
\text { Value }\end{array}$ & D.F & P-Value & Decision \\
\hline 1 & Accident type \& injury type & 132.488 & 2 & 0.0 & Reject \\
\hline 2 & Time and injury type & 55.910 & 23 & 0.0 & Reject \\
\hline 3 & weekdays and injury type & 2.104 & 6 & 0.910 & Accept \\
\hline 4 & Month\& injury type & 29.971 & 11 & 0.02 & Reject \\
\hline 5 & Governorate and injury type . & 254.951 & 11 & 0.0 & Reject \\
\hline 6 & Territory and injury type. & 5.147 & 2 & 0.076 & Accept \\
\hline 7 & weather condition and injury type & 11.043 & 5 & 0.05 & Reject \\
\hline 8 & Road surface condition and injury type & 15.562 & 6 & 0.016 & Reject \\
\hline 9 & Light Condition and injury type & 24.291 & 5 & 0.0 & Reject \\
\hline 10 & Age group and injury type & 57.252 & 20 & 0.0 & Reject \\
\hline 11 & Speed limit and injury type & 73.485 & 11 & 0.0 & Reject \\
\hline 12 & Gender and injury type & 3.262 & 1 & 0.07 & Accept \\
\hline
\end{tabular}

Note. The expected value of each cell $>5$.

\section{Groupe (II)}

H13: There is no difference in:

I) The means of factor (accident type) at (0.05) level.

II) The means of factor (injury type) at (0.05) level.

H14: There is no difference in:

I) The means of factor (time ) at (0.05) level.

II) The means of factor (injury type) at (0.05) level

H15: There is no difference in

I) The means of factor (Weekdays) at (0.05) level.

II) The means of factor (injury type) at (0.05) level.

H16: There is no difference in

I) The means of factor (Month) at (0.05) level.

II) The means of factor (injury type) at (0.05) level.

H17: There is no difference in:

I) The means of factor (Governorate) at (0.05) level.

II) The means of factor (injury type) at (0.05) level.

H18: There is no difference in:

I) The means of factor (Territory) at (0.05) level.

II) The means of factor (injury type) at (0.05) level.

H19: There is no difference in: 
I) The means of factor (weather condition) at (0.05) level.

II) The means of factor (injury type) at (0.05) level.

H20: There is no difference in:

I) The means of factor (Road surface condition) at (0.05) level.

II) The means of factor (injury type) at (0.05) level.

H21: There is no difference in:

I) The means of factor (Light Condition ) at (0.05) level.

II) The means of factor (injury type) at (0.05) level.

H22: There is no difference in:

I) The means of factor (Age group) at (0.05) level.

II) The means of factor (injury type) at (0.05) level.

$\mathrm{H} 23$ : There is no difference in:

I) The means of factor (Speed limit) at (0.05) level.

II) The factor ( injury type) at (0.05) level.

$\mathrm{H} 24$ : There is no difference in:

I) The means of factor (Gender ) at (0.05) level.

II) The means of factor (injury type) at (0.05) level.

Hypothesis testing results as the following:

Table 4. Shown the test of two-way Anova

\begin{tabular}{|c|c|c|c|c|c|c|c|}
\hline $\begin{array}{l}\text { Hypothesis } \\
\mathrm{No}\left(\mathrm{H}_{0}\right)\end{array}$ & Source & $\begin{array}{l}\text { Type II Sum of } \\
\text { Squares }\end{array}$ & $\mathrm{df}$ & Mean Square & F-Ratio & P-value & Decision \\
\hline \multirow[t]{2}{*}{13} & Accident Type & 79314790915.650 & 2 & 39657395457.825 & 51367.596 & 0.0 & Reject \\
\hline & Injury Type & 38577460686.245 & 1 & 38577460686.245 & 49968.773 & 0.0 & Reject \\
\hline \multirow[t]{2}{*}{14} & Time & 397429230.067 & 23 & 17279531.742 & 5188.678 & 0.0 & Reject \\
\hline & Injury Type & 473093943.570 & 1 & 473093943.570 & 142060.103 & 0.0 & Reject \\
\hline \multirow[t]{2}{*}{15} & Weekdays & 73955741.572 & 6 & 12325956.929 & 26750.916 & 0.0 & Reject \\
\hline & Injury Type & 4137866031.124 & 1 & 4137866031.124 & 8980374.245 & 0.0 & Reject \\
\hline \multirow[t]{2}{*}{16} & Month & 145138092.301 & 11 & 13194372.027 & 11909.422 & 0.0 & Reject \\
\hline & Injury Type & 1427657434.981 & 1 & 1427657434.981 & 1288623.282 & 0.0 & Reject \\
\hline \multirow[t]{2}{*}{17} & Governorate & 43706035560.398 & 11 & 3973275960.036 & 11382.433 & 0.0 & Reject \\
\hline & Injury Type & 7189777381.760 & 1 & 7189777381.760 & 20596.898 & 0.0 & Reject \\
\hline \multirow[t]{2}{*}{18} & Territory & 56607141014.131 & 2 & 28303570507.066 & 64270.906 & 0.0 & Reject \\
\hline & Injury Type & 36791467282.519 & 1 & 36791467282.519 & 83544.970 & 0.0 & Reject \\
\hline \multirow[t]{2}{*}{19} & Weather Condition & 48335268678.581 & 5 & 9667053735.716 & 31657.417 & 0.0 & Reject \\
\hline & Injury Type & 180573584916.526 & 1 & 180573584916.526 & 591337.697 & 0.0 & Reject \\
\hline \multirow[t]{2}{*}{20} & $\begin{array}{l}\text { Road } \\
\text { Condition }\end{array}$ & 56569515705.298 & 6 & 9428252617.550 & 22550.791 & 0.0 & Reject \\
\hline & Injury Type & 174623462163.212 & 1 & 174623462163.212 & 417669.894 & 0.0 & Reject \\
\hline \multirow[t]{2}{*}{21} & Light Condition & 155488298086.374 & 5 & 31097659617.275 & 31635.400 & 0.0 & Reject \\
\hline & Injury Type & 72926876014.746 & 1 & 72926876014.746 & 74187.928 & 0.0 & Reject \\
\hline \multirow[t]{2}{*}{22} & Age Group & 978693030.015 & 20 & 48934651.501 & 6557.143 & 0.0 & Reject \\
\hline & Injury Type & 665758408.954 & 1 & 665758408.954 & 89210.264 & 0.0 & Reject \\
\hline \multirow[t]{2}{*}{2} & Speed Limit & 16790035629.429 & 11 & 1526366875.403 & 10421.079 & 0.0 & Reject \\
\hline & Injury Type & 8468264633.486 & 1 & 8468264633.486 & 57816.018 & 0.0 & Reject \\
\hline \multirow[t]{2}{*}{24} & Gender & 88434154021.917 & 1 & 88434154021.917 & 148594.926 & 0.0 & Reject \\
\hline & Injury Type & 80468570242.478 & 1 & 80468570242.478 & 135210.444 & 0.0 & Reject \\
\hline
\end{tabular}




\section{Results}

Based on the analysis made, the following are the main results:

There is statistical significant relationship between type of injury (slight, sever) and traffic accident type (Collision, Pedestrian, Turnover).

Time (0.00-00.59, 01.00-01.59 .....23.00-23.59).

Month (January, February.......December) Governorate (Amman, Irbed.........Ajloun).

Light condition (Day Light, Night with Sufficient Light.......Sunset).

Speed limits $(10,20 \ldots . .120)$.

Age group $(0-2,3-5 \ldots . .60+)$.

There is no statistical significant relationship between type of injury (slight, sever) and Weekdays (Saturday, Sunday.......Friday).

Territory (Central Region, North Region, South Region).

Weather condition (Clear, Fog.......Dust).

Gender (Male, Female).

The chi-square test is inconclusive to test the following hypotheses:

There is no statistical significant relationship at between type of injury (slight, sever) and road surface condition (Dry, Wet......Sandy) at (0.05) level.

There is no difference in the means of the following factors: Accident Type, Time, Weekdays, Month, Governorate, Territory, Weather Condition, Road Surface Condition, Light Condition, Age Group, Speed Limit, Gender, at (0.05) level.

There is difference in means of factor X2 (injury type) at (0.05) level.

\section{Conclusions}

Based on the results, the researcher recommended the following:

- Harsher penalties on perpetrators traffic accidents.

- Reregulation's in legislation and laws governing drivers.

- Take advantage of these results in future traffic studies.

\section{References}

Abu- Salih, M., \& Awad, A. (1983). Introduction to Statistics. Jhon Wiley \& Sons.

Deven, E. L., \& Hampton, C. G. (2004). The Fatality and Injury Risk of Light Truck Impacts with Pedestrians in the United States. Accident Analysis and Prevention, 36(2), 295-304. http://dx.doi.org/10.1016/S0001-4575(03)00007-1

Donald, R. (2006). Cooper/ Pamela S. Schindler, Business Research Methods, ninth edition. McGraw Hill.

Gerald, K. (2010). Statistics For Business And Economics (11th ed.). South Western.

Golob, T., \& Recker, W. (2003). Relationships among Urban Freeway Accidents, Traffic Flow, Weather, and Lighting Conditions. Journal of transportation Engineering, 129(4), 342-353. http://dx.doi.org/10.1061/9780784412442.255

Hallvard, G., Per, T. N., Asbjrg, S. C., Sven, O. S. (2011). Alcohol Psychoactive Drugs and Fatal Road Traffic Accidents in Norway: A case-Control Study. Accident Analysis and Prevention, 43, 1197-1203. http://dx.doi.org/10.1016/j.aap.2010.12.034

Hu, S., \& Xiang, Q. (2012). Characteristics Analysis of Traffic Accidents on Rural Roads. CICT, 2506-2513. http://dx.doi.org/10.1061/9780784412442.255

James, T. M., George, B., Terry, S. (2012). Statistics For Business And Economics (12th ed.).Pearson.

Li, Y., \& Li, X. (2011). Driver Workload Mutations Induced Road Analysis of Traffic Accidents in the Rural-Urban Continuum. ICTE, 3274-3279. http://dx.doi.org/10.1061/9780784412442.228

Lind, M., \& Wathen. (2005). Basic Statistics for Business and Economic (5th ed.). McGraw Hill.

Lind, M., \&Wathen . (2004). Statistical Techniques in Business and Economics (12th ed.). McGraw Hill. 
Ma, X., Zhang, Z., Li, Z., \& Ding, J. (2011). Modeling and Analysis of Traffic Accidents' Inducements Based on Factorial Experiment Method. ICCTP, 1988-1998. http://dx.doi.org/10.1061/41186\%28421\%29197

Mary, E. T., John, D., Elizabeth, C., \& Richard, M. (1995). Risk Factors for Serious Injury During Falls by Older Persons in the Community. Journal of the American Geriatrics Society, 43(11), 1214-1221. http://dx.doi.org/10.1097/00004045-199607000-00013

Sandvik, H., Seim, A., Vanvik, A., \& Hunskaar, S. (2000). A severity index for epidemiological surveys of Female urinary incontinence: Comparison with 48-hour pad-weighing tests. Neurourology and Urodynamics, Journal, 19(2), 137-145.http://dx.doi.org/10.1002/(SICI)1520-6777(2000)19:23.0.CO;2-G

Statistical report of Traffic Accidents in Jordan. (2014). The Hashemite Kingdom of Jordan, Amman, Ministry of Interior, the General Security Directorate, the Jordanian Traffic Institute.

Zhang, K., Yao, L., \& Li, G. (2012). Relationship between Road Lighting and Traffic Accidents. ICLEM, 640-646. http://dx.doi.org/10.1061/9780784412602.0099

Zoubi, M. B. T., \& Abbas. (2012). The statistical system (SPSS) understand and analyze statistical data. Dar Wael for Publication and Distribution (3rd ed.). Amman, Jordan.

\section{Copyrights}

Copyright for this article is retained by the author(s), with first publication rights granted to the journal.

This is an open-access article distributed under the terms and conditions of the Creative Commons Attribution license (http://creativecommons.org/licenses/by/3.0/). 